\title{
Analyse structurelle des systèmes agroforestiers à base de Moringa oleifera Lam. dans les vallées du fleuve Niger et du Goulbi de Maradi (Niger)
}

\author{
Younoussou $\mathrm{RABO}^{1 *}$, Sitou LAWALI ${ }^{1}$, Aissetou Yayé DRAME ${ }^{2}$ et Ali MAHAMANE ${ }^{3,4}$ \\ ${ }^{1}$ Université Dan Dicko Dankoulodo de Maradi, Niger. \\ ${ }^{2}$ Secrétariat exécutif, ANAFE, Kenya. \\ ${ }^{3}$ Université Abdou Moumouni de Niamey, Niger. \\ ${ }^{4}$ Université de Diffa, Niger. \\ *Auteur correspondant ; E-mail : raboyounoussou@gmail.com; Tel :( 00227) 96388953
}

\section{RESUME}

Les structures des systèmes agroforestiers à base de Moringa oleifera ont fait l'objet de suivi et d'analyses approfondies sur les sites de la vallée du fleuve Niger et du Goulbi de Maradi. Le suivi a porté sur la détermination des cultures maraîchères associées au M. oleifera, la durée ainsi que l'arrangement spatial des composantes de cette association. Les données ont été collectées à l'aide d'une fiche qui renseigne sur les paramètres à étudier. Aussi, des interviews semi-structurées ont été organisées avec les exploitants pour appréhender les motivations qui sous-tendent leur choix d'associer telle ou telle culture au M. oleifera. Il ressort de cette étude que sur les deux (2) sites, l'agrosylviculture domine avec plusieurs formes d'association du M. oleifera avec les cultures maraichères notamment Solanum melongena ( $24 \%$ des cultures associées au $M$. oleifera dans la vallée du fleuve) et Lycopersicon lycopersicum L (50\% des cultures associées au M. oleifera dans le Goulbi de Maradi). Les raisons avancées par les exploitants pour choisir les cultures associées au $M$. oleifera sont d'ordre édaphique ou socioéconomique. Les superficies moyennes exploitées représentent 0,1915 $\pm 0,1707$ ha/exploitant et $0,185 \pm 0,0766$ ha/exploitant respectivement dans la vallée du fleuve Niger et le Goulbi de Maradi.

(c) 2015 International Formulae Group. All rights reserved.

Mots clés : Analyse structurelle, systèmes agroforestiers, M. oleifera, cultures maraîchères, Vallée du fleuve Niger, Goulbi de Maradi.

\section{Structural analysis of agroforestry systems of Moringa oleifera Lam. in the valleys of the Niger River and Goulbi Maradi (Niger)}

\begin{abstract}
The structures of agroforestry systems of Moringa oleifera were monitored and analyzed on the sites of the valley of the River Niger and Goulbi Maradi. Monitoring focused on the determination of vegetable crops associated with $M$. oleifera, duration and spatial arrangement of the components of this combination. Data were collected using a card which provides information on the parameters studied. Also, semi-structured interviews
\end{abstract}


were held with operators to understand the motivations underlying their choice to associate a particular culture with $M$. oleifera. It appears from this study that among the two (2) sites, agroforestry dominates with several forms of association of M. oleifera with vegetable crops including Solanum melongena (24\% of the cultures associated with $M$. oleifera in the river valley) and Lycopersicon lycopersicum L (50\% of the cultures associated with $M$. oleifera in Goulbi Maradi). The reasons given by farmers to choose crops associated with M. oleifera are edaphic or socioeconomic. The average area exploited represent $0.1915 \pm 0.1707$ ha/operator and $0.185 \pm 0.0766$ ha/operator respectively in the valley of the River Niger and Goulbi Maradi.

(C) 2015 International Formulae Group. All rights reserved.

Keywords: Structural analysis, agroforestry system, M. oleifera, vegetable crops, Niger River valley, Goulbi Maradi.

\section{INTRODUCTION}

Pratiquée pendant des millénaires par les paysans africains avec une stabilité remarquable, l'agroforesterie évolue et attire l'attention des chercheurs (ANAFE-RAFT Sahel, 2006). De nombreuses études scientifiques ont montré l'intérêt accordé à ce mode d'utilisation des terres qu'est l'agroforesterie, qui fait intervenir ce qui est communément appelé les arbres ou arbustes à usage multiple, tel que Moringa oleifera Lam.

En effet, les interactions écologiques entre les arbres/arbustes et les cultures sont bénéfiques (Burgess al., 2004) parce que les ligneux ont un effet sur la fertilité des sols à travers la fixation d'azote atmosphérique, la production de matière organique par les débris ligneux tombés, le recyclage des éléments nutritifs du sol améliorant ainsi les rendements des cultures (Rivest et al., 2007). Ils permettent aussi de protéger le sol contre l'érosion hydrique et éolienne. Les arbres et arbustes sont de ce fait d'une grande utilité pour l'homme et les animaux car combinant plusieurs fonctions et services.

Les feuilles, fruits et fleurs de Moringa oleifera sont régulièrement utilisés dans l'alimentation humaine, la pharmacopée et dans la fabrication des produits cosmétiques. En effet, Moringa oleifera a des teneurs élevées en protéines, en lipides, en fibres et en produits amylacés (Foidl et al., 2001).Ses feuilles riches en fer, en calcium et en phosphore (Besse, 1998) sont utilisées dans la préparation de soupe, de sauce et du couscous en Afrique.
D'après Saint Sauveur (1997), les fruits du Moringa oleifera ont la capacité de purifier l'eau, le miel et le lait. En effet, les fruits riches en phosphore et en protéines peuvent également être consommés comme légumes verts (Fahey, 2005). Fuglie (2002) indique que le bois du Moringa oleifera produit une teinture bleue utilisée en Jamaïque et au Sénégal. D'après, le même auteur, l'écorce de l'arbre peut être transformée en fibre pour la production de cordages ou de nattes. Il a aussi été rapporté que les feuilles, les fruits, les graines, les racines, l'écorce mais aussi les fleurs possèdent chacun des vertus médicinales particulières (Fuglie, 2002).

Au Niger, Moringa oleifera est cultivé en association avec les cultures maraîchères dans la vallée du fleuve Niger et le Goulbi de Maradi (Gamatié, 2001). Les systèmes agroforestiers à base de Moringa Oleifera procurent l'essentiel de la subsistance des exploitants. Les exploitants de ces systèmes utilisent les revenus tirés de la vente de leurs extrants pour résoudre aussi les problèmes d'ordre social tels les mariages et les baptêmes. Par ailleurs, il faut souligner que Moringa oleifera n'est pas exclusivement destiné à l'alimentation; elle est également utilisée comme médicament (Mawouma, 2014). Cependant, bien que le maraîchage soit une pratique très développée au Niger, l'association de cultures maraichères avec Moringa oleifera, n'a pas fait l'objet de beaucoup d'attention de la part des chercheurs. La présente étude se propose donc de contribuer à combler cette lacune en faisant l'inventaire des cultures associées au Moringa 
oleifera dans les vallées du fleuve Niger et du Goulbi de Maradi. L'étude porte également sur la durée et l'inventaire des types d'associations de cultures incluant Moringa oleifera. L'étude s'intéresse aussi aux superficies occupées par ces systèmes à l'intérieur de chaque site. Au niveau de chaque exploitation, l'analyse structurale ainsi que la répartition des peuplements en fonction des différents systèmes agroforestiers tels que définit par (ANAFE-RAFT Sahel, 2006) ont été effectuées. Les systèmes d'utilisation des terres considérés sont:

$>$ L'agrisylviculture qui regroupe tous les systèmes d'utilisation des terres dans lesquels des ligneux pérennes sont associés aux cultures que ce soit de manière concomitante ou séquentielle ;

$>\quad$ Le sylvopastoralisme qui regroupe les systèmes d'utilisation des terres qui associent délibérément les ligneux aux animaux ou les ligneux dans les espaces pastoraux afin d'améliorer les fourrages et de produire du bois d'œuvre ou de service ;

L'agrosylvopastoralisme qui est l'ensemble des modes d'utilisation des terres où les trois principales composantes de l'agroforesterie sont associées. Ce système est d'une grande importance dans les régions où l'agriculture et l'élevage constituent les activités principales des communautés rurales.

\section{MATERIEL ET METHODES \\ Site de l'étude}

L'étude a été réalisée au Niger, sur deux sites localisés respectivement au niveau de la vallée du fleuve Niger dans la région de Niamey, et au niveau du Goulbi de la région de Maradi située au Sud-Est du pays (Figure 1). Sur chaque site, deux villages où le $M$. oleifera est associé aux cultures maraîchères ont été choisis. Ainsi, les villages de Saguia et Saga Fondo dans la vallée du fleuve Niger et les villages de Djirataoua et Tibiri dans le Goulbi de Maradi ont été sélectionnés sur la base des critères suivants : Existence d'un site maraîcher, présence de variété locale de Moringa oleifera dans les associations culturales au niveau des parcelles, longue expérience des exploitants dans l'agroforesterie. Notons aussi que les deux sites diffèrent par la nature du cours d'eau : le Goulbi de Maradi est une vallée qui n'est active que pendant la saison des pluies et le fleuve Niger qui est un cours d'eau permanent.

\section{Collecte de données}

$\mathrm{Au}$ cours de cette étude, deux méthodes de collecte des données ont été utilisées: des enquêtes auprès des exploitants et un suivi de parcelles sur le terrain.

Sur chaque site, une étude exploratoire a été réalisée afin de déterminer les différents systèmes agroforestiers à base de M. oleifera. Pour apprécier la diversité des systèmes, un échantillon de 24 exploitations a été sélectionné de manière aléatoire sur chacun des sites. Cependant, après le démarrage des activités, 4 des exploitations de la vallée du fleuve ont été abandonnées par les exploitants.

Le suivi et la collecte des données ont duré six (6) mois (d'octobre 2013 à mars 2014) correspondant à la période des cultures marâichères. A cet effet, une fiche de suivi a été élaborée et renseignée toutes les semaines. Cette fiche a permis de déterminer les cultures maraîchères associées au $M$. oleifera, la durée de cette association ainsi que l'arrangement spatial des composantes de cette association. Ensuite, des interviews semi-structurées ont été organisées avec les exploitants pour appréhender les motivations qui sous-tendent leur choix d'associer telle ou telle culture au M. oleifera.

Les réponses des fiches ont été codifiées puis enregistrées grâce au logiciel IBM SPSS Statistics version 20. Ce qui a permis de déterminer la fréquence des modalités pour chaque variable étudiée. Des tests de comparaison de Kruskal-Wallis ont été effectués entre les moyennes des superficies occupées par ses systèmes sur les sites avec le logiciel Minitab. La comparaison des résultats exprimés en pourcentage a été réalisée en appliquant le test Khi-deux de Pearson. Une valeur de $\mathrm{p}<0,05$ a été considérée comme statistiquement significative. 


\section{RESULTATS}

Typologie des systèmes agroforestiers incluant M. oleifera

Les exploitations ont été classées en fonction de deux (2) grands types de systèmes de production pratiqués (Tableau 1). L'agrisylviculture concerne respectivement 95\% des exploitations enquêtées dans la vallée du fleuve et $100 \%$ dans le Goulbi de Maradi. Il n'y a pas de différence significative entre les proportions citées ci-haut.

\section{Arrangement spatial des composantes associées}

Certains exploitants associent le $M$. oleifera aux cultures maraîchères en les mélangeant sur les unités d'exploitation formant une mosaïque de cultures maraîchères et de $M$. oleifera alors que d'autres font l'association en cultures intercalaires. Dans le premier cas, il a été utilisé le terme « cultures en mosaïque » et, «cultures intercalaires» dans le second cas. Les Figures 2, 3 et 4 illustrent quelques types d'association de $M$. oleifera avec les cultures. L'analyse des données révèle que dans la vallée du fleuve, les exploitants ne pratiquent pas de cultures intercalaires alors que dans le Goulbi de Maradi les deux formes existent dans les proportions de $37,5 \%$ et $62,5 \%$ des exploitations respectivement pour la culture en mosaïque et la culture intercalaire (Tableau 2). Le test de khi-deux montre que les proportions de la culture en mosaïque dans la vallée du fleuve (100\%) et dans le Goulbi de Maradi (37,5\%) sont significativement différentes et que les proportions dans le Goulbi de Maradi de 37,5\% de culture en mosaïque et $62,5 \%$ de culture intercalaire le sont également.

\section{Durée de l'association de $M$. oleifera avec les cultures maraîchères}

Dans les systèmes agroforestiers où il est associé aux cultures maraîchères, $M$. oleifera joue très souvent un rôle secondaire pendant la période de l'association. En effet, pendant cette période, les opérations et techniques culturales dans le système sont tributaires de la culture associée. Tout l'espoir des exploitants reposent sur ce qu'ils pourraient tirer des produits des cultures maraîchères, le M. oleifera ne leur vient qu'en appoint. L'intégration de M. oleifera dans les systèmes d'utilisation des terres date d'au moins une vingtaine d'années dans le Goulbi de Maradi et de 15 ans dans la vallée du fleuve Niger (Figure 5). De plus, les exploitations vieilles au plus de quatre (4) ans sont les plus représentées. En effet, elles représentent $55 \%$ et $54 \%$ des exploitations respectivement dans la vallée du fleuve et le Goulbi de Maradi. Ces proportions ne sont pas significativement différentes. Les exploitants dont l'association a un âge compris entre cinq (5) et dix (10) ans représentent $30 \%$ et $20 \%$ des exploitations respectivement dans la vallée du fleuve et dans le Goulbi de Maradi ; proportions qui ne sont pas significativement différentes. De même, les proportions (15\% dans la vallée du fleuve et $25 \%$ dans le Goulbi de Maradi) des exploitations qui ont dix (10) ans et plus ne sont pas significativement différentes $(\mathrm{p}=0,07)$.

\section{Cultures associées au Moringa oleifera}

Pendant la saison sèche froide de la campagne 2013-2014, les cultures presentées dans le Tableau 3 ont été répertoriées dans les systèmes agroforestiers à base de $M$. oleifera sur les deux sites d'étude. Ce tableau montre une diversification culturale aussi bien dans la vallée du fleuve que dans le Goulbi de Maradi. Cependant, l'oignon et le piment sont associés au M. oleifera sur les deux sites alors que le chou, l'aubergine, le concombre et l'oseille ne sont associés au M. oleifera que dans les systèmes agroforestiers de la vallée du fleuve et que la laitue et le maïs sont associés au M. oleifera seulement dans les systèmes du Goulbi de Maradi. Il ressort également de l'analyse de ce tableau que la 
culture la plus fréquente dans le Goulbi de Maradi est la tomate avec une proportion de $50 \%$ des cultures associées au M. oleifera suivie de la laitue ( $23 \%$ des cultures associées au $M$. oleifera) alors que dans la vallée du fleuve, c'est l'aubergine (24\% des cultures associées au $M$. oleifera) qui domine les cultures, suivie de l'oseille, la tomate et l'oignon à égale proportion de $16 \%$ des cultures associées au $M$. oleifera.
Les superficies moyennes exploitées par les systèmes agroforestiers à base de $M$. oleifera sont de $0,1915 \pm 0,1707$ ha et 0,185 $\pm 0,0766$ ha/exploitant respectivement dans la vallée du fleuve et le Goulbi de Maradi. Le test de Kruskal-Wallis montre qu'il y'a une différence significative $(\mathrm{P}=0,028)$ entre les moyennes des superficies exploitées par les systèmes dans la vallée du fleuve et le Goulbi de Maradi.
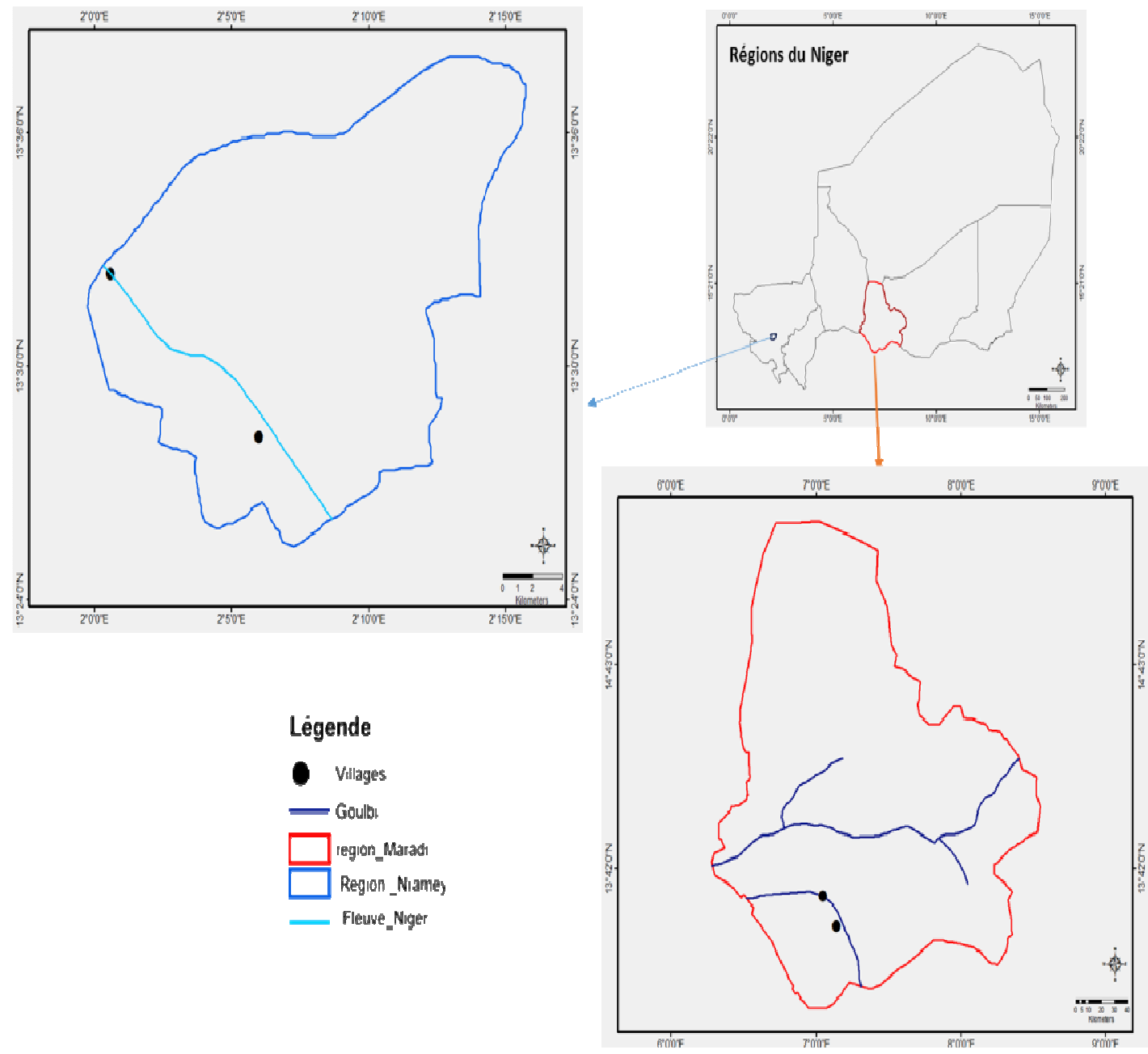

Figure 1 : Localisation des sites de l'étude. 


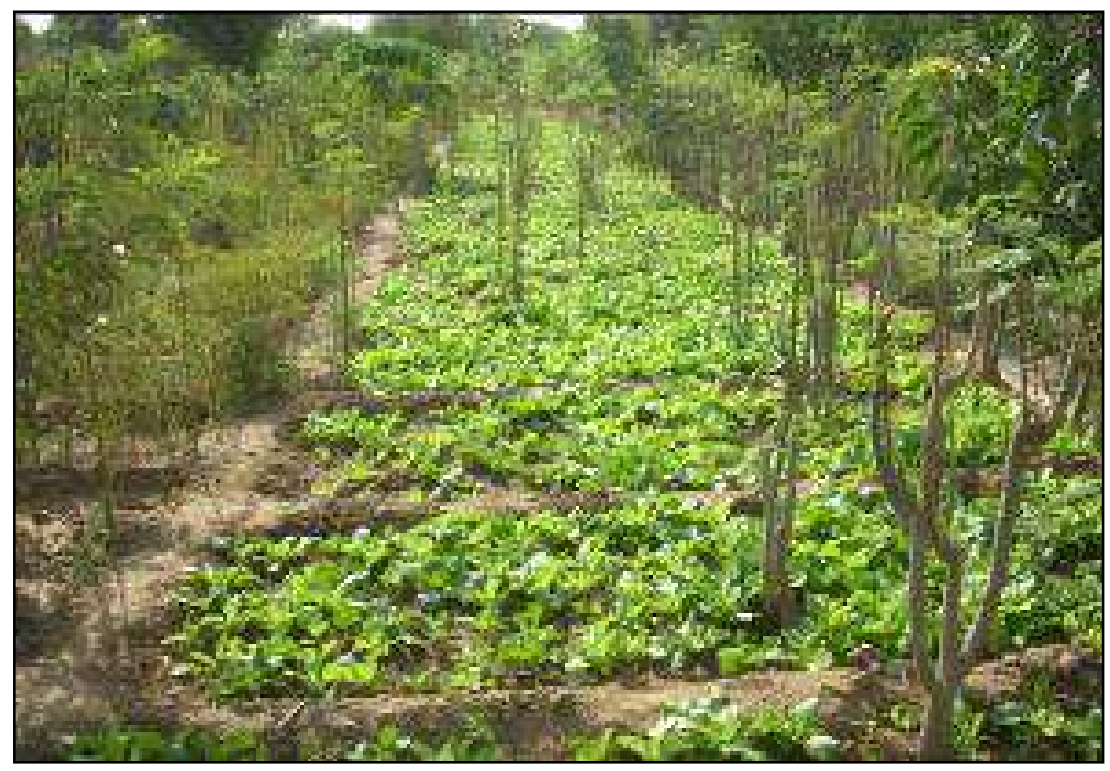

Figure 2 : Culture de M. oleifera en association avec la laitue.

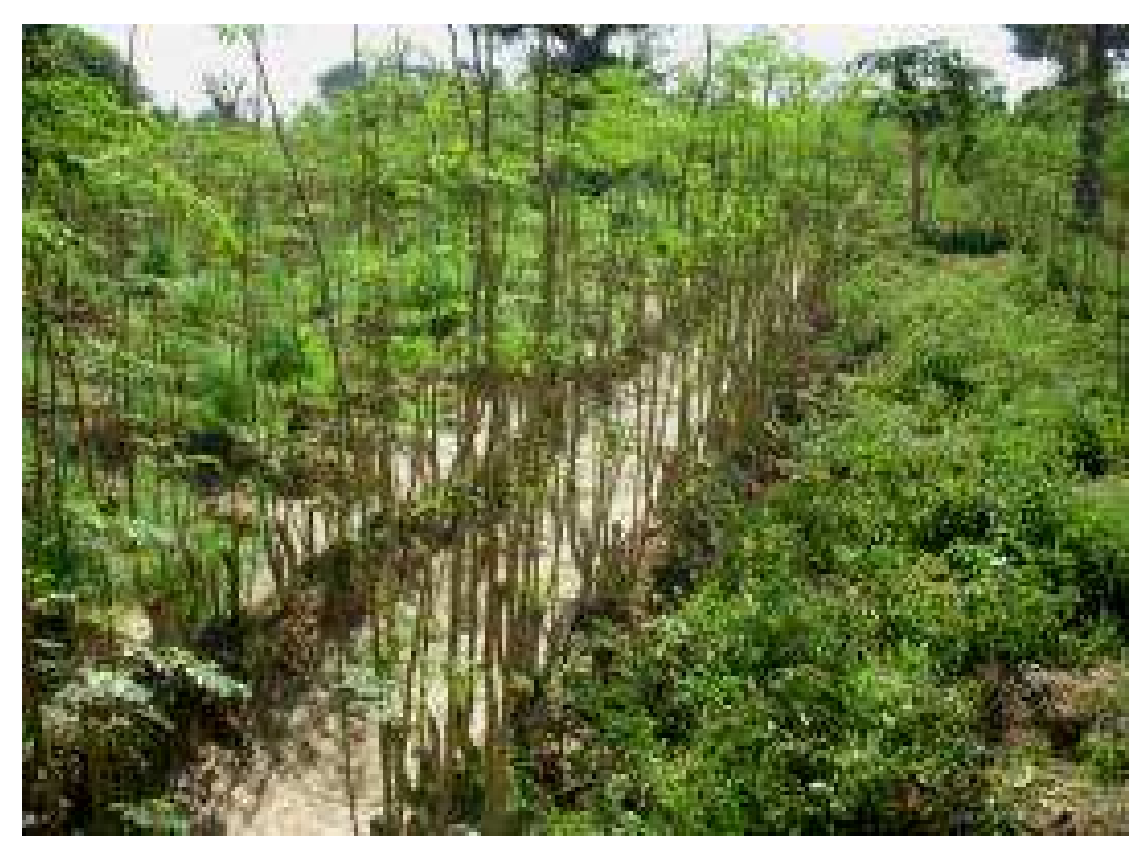

Figure 3 : Plantation de M. oleifera en bordure des canaux d'irrigation d'une parcelle de tomate. 


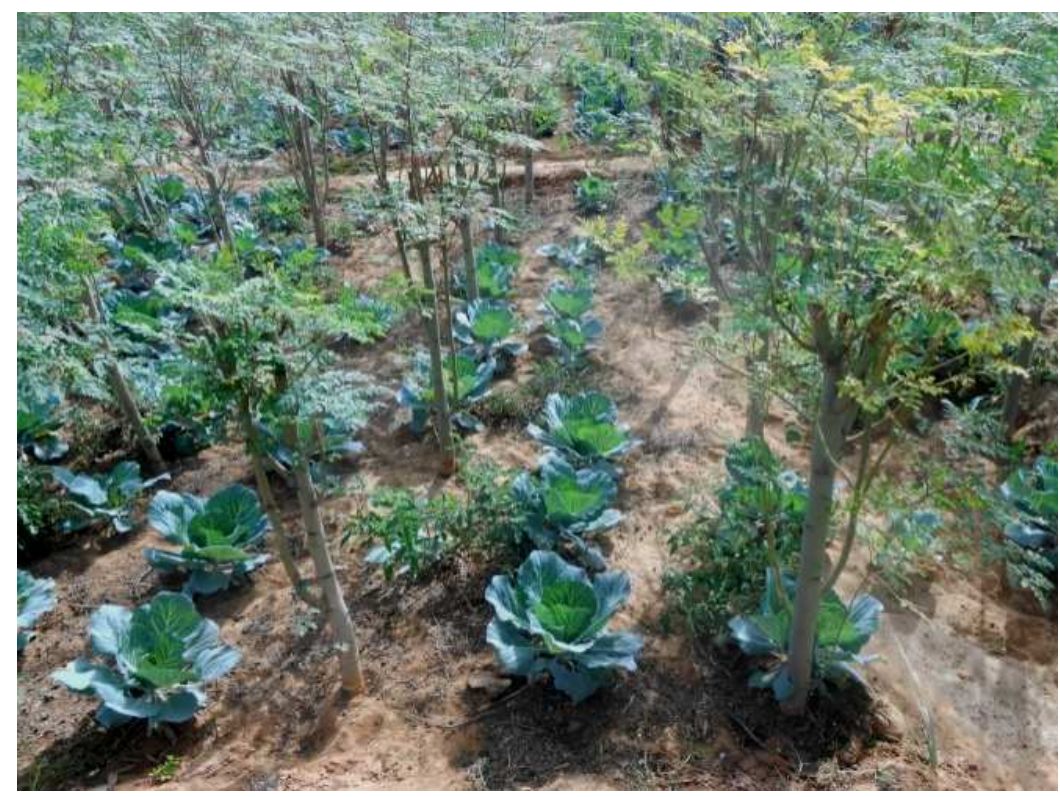

Figure 4: Culture de M. oleifera en association avec le chou pommé.

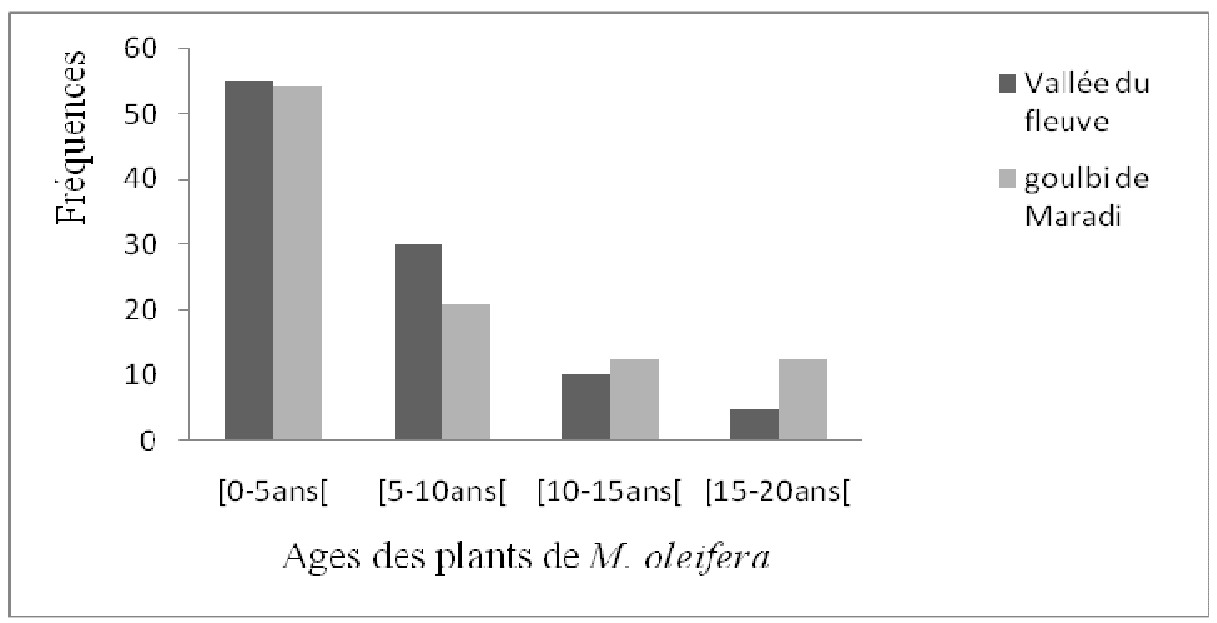

Figure 5 : Fréquences des âges des plants de M. oleifera dans les vallées du fleuve et du Goulbi de Maradi.

Tableau 1 : Fréquences relatives (\%) des catégories structurales de l'exploitation selon les sites.

\begin{tabular}{lccc}
\hline & Agrisylviculture (\%) & Agrosylvopastoralisme (\%) & p \\
\hline Vallée du fleuve Niger & 95 & 5 & 1 \\
Goulbi de Maradi & 100 & 0 & \\
P & 0,02 & & 1
\end{tabular}


Tableau 2 : Fréquences relatives (\%) des modes d'association de M. oleifera par rapport aux cultures associées.

\begin{tabular}{lccc}
\hline Sites d'exploitation & $\begin{array}{c}\text { Cultures en } \\
\text { mosaïque (\%) }\end{array}$ & $\begin{array}{c}\text { Cultures intercalaires } \\
(\boldsymbol{\%})\end{array}$ & $\boldsymbol{p}$ \\
\hline Vallée du fleuve Niger & 100 & 0 & 1 \\
Goulbi de Maradi & 37,5 & 62,5 & $<0,001$ \\
$P$ & $<0,001$ & 1 & \\
\hline
\end{tabular}

Tableau 3 : Fréquences relatives (\%) des cultures associées au M. oleifera dans la vallée du fleuve et le Goulbi de Maradi.

\begin{tabular}{llcc}
\hline Noms scientifiques & Noms en français & Vallée du fleuve & Goulbi de Maradi \\
\hline Lycopersicon lycopersicum & Tomate & 16 & 50 \\
Solanum melongena & Aubergine & 24 & 0 \\
Brassica oleracea & Chou & 13 & 0 \\
Cucurbita moschata & Courge & 11 & 0 \\
Allium cepa & Oignon & 16 & 23 \\
Capsicum annuum & Piment & 2 & 12 \\
Cucumis sativus & Concombre & 2 & 0 \\
Hibiscus sabdariffa & Oseille de Guinée & 16 & 0 \\
Zea Mays & Maïs & 0 & 4 \\
Lactuva sativa & Laitue & 0 & 11 \\
Total & & $100 \%$ & $100 \%$ \\
\hline
\end{tabular}

\section{DISCUSSION}

Le choix des composantes associées dans les systèmes agroforestiers à base de $M$. oleifera se justifie par le rôle assigné à ces systèmes. En effet, les exploitants de ces systèmes affirment faire une utilisation rationnelle des terres en combinant $M$. oleifera et cultures maraîchères sur une même superficie. Selon une étude menée par Gamatié (2001) à Niamey et à Maradi, la production des feuilles de M. oleifera est faite en association avec les cultures pluviales (en saison hivernale) et avec les cultures maraîchères (en saison sèche). En 1997, Saint Sauveur a révélé deux pratiques agroforestières à base du M. oleifera dans le périmètre irrigué de Djirataoua (Goulbi de Maradi): la haie vive et les cultures intercalaires. Par ailleurs, dans ces deux (2) formes d'association $M$. oleifera-cultures maraîchères, les deux composantes bénéficient des mêmes pratiques agricoles et tous les apports des fertilisants sont bénéfiques à toutes les cultures associées.

Dans la vallée du fleuve, $100 \%$ des exploitants pratiquent la culture en mosaïque. Par contre, dans le Goulbi de Maradi les deux formes existent avec une prédominance de la culture intercalaire. Pour les exploitants de la vallée du fleuve, cette association permet d'occuper l'espace pour une production optimale des feuilles de M. oleifera qui servent également d'ombrage pour les cultures maraîchères en période sèche chaude. En période sèche froide, les plants de $M$. oleifera sont généralement coupés pour installer les cultures maraîchères. Cette coupe permet un rajeunissement des rameaux et l'augmentation de la production des feuilles et de bonne qualité. Quant aux exploitants du Goulbi de Maradi, les avis sont partagés. Certains pensent qu'il serait bénéfique pour les cultures maraîchères et le $M$. oleifera d'être disposés en bandes intercalaires de $M$. oleifera et de 
cultures d'où la culture intercalaire. Dans ces exploitations, $M$. oleifera n'est pas considéré comme une culture secondaire. Il reçoit tout comme les cultures maraîchères les mêmes traitements et bénéficie d'une attention particulière pour les exploitants des sites du Goulbi que ceux de la région du fleuve. Une étude menée au Niger en 1997dans les régions de Maradi et Niamey par Saint Sauveur, a révélé que dans la région de Maradi, les exploitants pratiquent la culture de M. oleifera en monoculture, en haie et en culture en couloirs. D'après le même auteur, dans la parcelle des allées sont mises en place avec des écartements qui varient entre 3 et $4 \mathrm{~m}$ entre les haies de M. oleifera.

L'intégration du M. oleifera dans les systèmes d'utilisation des terres est plus ancienne dans le Goulbi de Maradi. Selon (Saint Sauveur, 1997) Maradi est la plus ancienne zone de production du M. oleifera au Niger (il était cultivé depuis environ 50 ans en 1997) alors que son introduction date des années 1983/84 dans la vallée du fleuve. Pourtant, les résultats ont montré des distributions de fréquence similaires des plantes en fonction des classes d'âge sur les deux sites d'études. Le rajeunissement des peuplements observés dans les sites peut s'expliquer par une bonne maîtrise des pratiques sylvicoles par les paysans.

Culture fruitière et légumière, $M$. oleifera occupe de plus en plus de l'espace dans les exploitations pour d'une part diversifier les menus quotidiens mais également valoriser ses qualités nutritionnelles. Il a été répertorié, au total, huit espèces associées au M. oleifera dans la vallée du fleuve et cinq dans le Goulbi de Maradi. Deux raisons peuvent expliquer le choix de ces cultures associées au M. oleifera. La première, est socioéconomique et, la deuxième est liée à la nature des sols. En effet, d'après les exploitants, certains sols sont impropres à la plupart des cultures. Il s'agit d'après eux, des sols «fatigués » qui ne peuvent produire qu'un nombre limité de cultures dont entre autres l'oignon et l'oseille. Néanmoins, pour réussir la production, il est impératif d'apporter de la fumure organique appuyée éventuellement de la fumure minérale. D'autres exploitants affirment ne pas avoir le choix quand ils font de l'oignon. Leur position s'explique par le fait qu'à la récolte, l'oignon est très mal payé et surtout la production prend du temps. De plus, la conservation des bulbes d'oignon est très délicate car les exploitations peuvent perdre une partie ou presque la totalité des produits conservés. Quant à l'oseille, elle réussit certes sur des sols épuisés mais l'aspect économique de sa production est le plus souvent mis au devant. Il faut souligner que ce sont les jeunes feuilles de l'oseille de 30 à 45 jours qui sont coupées et vendues au marché. Ces feuilles sont beaucoup utilisées dans les sauces.

Les autres cultures associées au $M$. oleifera sont choisies pour des raisons socioéconomiques. L'oseille dans la vallée du fleuve, tout comme la laitue dans le Goulbi de Maradi, ont un cycle court par rapport aux autres cultures. Le cycle de ces cultures varie de 30 à 45 jours et offre aux exploitants l'avantage de faire trois (3) cycles contre un seul cycle pour les autres cultures qui font quatre (4) à cinq (5) mois en milieu paysan, ce qui procure aux exploitants une certaine stabilité économiques. Les proportions de $16 \%$ et $23 \%$ respectivement pour l'oseille dans la vallée du fleuve et la laitue dans le Goulbi de Maradi témoignent la place qu'occupe chacune de ces cultures dans les systèmes agroforestiers à base de M. oleifera.

Les cultures comme l'aubergine, en plus d'être moins exigeantes, présentent l'avantage de produire des fruits sur une très longue durée. C'est la raison fondamentale pour laquelle elle est choisie par les exploitants de la vallée du fleuve. D'où le taux de $24 \%$ observé dans la vallée du fleuve.

Une autre culture moins exigeante et de cycle court est la tomate mais dont les apports sont peu importants. En effet les proportions respectives de $16 \%$ et $50 \%$ de la tomate par rapport aux autres cultures maraîchères associées au $M$. oleifera observés dans la vallée du fleuve et le Goulbi de Maradi prouvent que cette culture a les 
faveurs des exploitants des deux sites. Or d'après ces derniers, la tomate fait partie des cultures rentables. Cependant, la tomate ne se conserve pas longtemps; ce qui constitue une contrainte à sa production.

Les courges représentent $11 \%$ des cultures maraîchères associées au $M$. oleifera dans la vallée du fleuve et constitue une des cultures les moins représentées. Cette culture n'est pas associée au $M$. oleifera dans le Goulbi de Maradi car étant même peu pratiquée dans cette zone vue qu'elle y est peu consommée.

Le piment est également associé au M. oleifera sur les deux sites dans les proportions de $2 \%$ et $12 \%$ respectivement dans la vallée du fleuve et le Goulbi de Maradi. Malgré cette faible proportion dans la vallée du fleuve, les exploitants reconnaissent que le piment est l'une des cultures qui, associées au M. oleifera, produit bien. Par ailleurs, les populations haoussa consomment plus le piment que celles du fleuve. D'où le taux de $12 \%$ dans le Goulbi de Maradi. Il faut reconnaître aussi que le piment ne constitue pas un aliment de base mais qu'il n'est utilisé que pour assaisonner les repas.

Le chou pommé est très prisé par la population de Niamey et ce, en toute période de l'année. Il est considéré comme légume feuille et est utilisé dans la sauce. Il se mange aussi bien cru que cuit. Cette culture n'a pas été enregistrée comme culture associée au $M$. oleifera dans le Goulbi de Maradi pourtant il est bien produit dans la zone. En effet, certains exploitants affirment que le chou pommé a un effet négatif sur la production de biomasse foliaire du $M$. oleifera. Ce qui fait qu'ils n'associent pas le chou pommé au $M$. oleifera.

Les superficies occupées par ces systèmes sont en moyenne de 0,1915 \pm 0,1707 ha/exploitant et $0,185 \pm 0,0766$ ha/exploitant respectivement dans la vallée du fleuve et dans le Goulbi de Maradi. Une étude menée dans la vallée du fleuve par Saint Sauver (2005) a révélé que les producteurs exploitent de petites superficies $(0,02$ ha à 0,47 ha). Dans la vallée du fleuve, les superficies cultivées varient de 0,02 ha à 0,5 ha alors que dans le Goulbi de Maradi elles varient de 0,12 ha à 0,5 ha. Cette situation est due à la difficulté qu'il y'a dans la gestion de ces systèmes mais aussi et surtout au manque de moyens financiers des exploitants.

\section{Conclusion}

L'analyse des systèmes agrofestiers à base de Moringa oleifera Lam. a révélé que ces systèmes contiennent essentiellement deux composantes à savoir le $M$. oleifera comme ligneux et les cultures maraîchères. Ces systèmes sont des anciennes pratiques aussi bien dans le Goulbi de Maradi que dans la vallée du fleuve. En effet, l'étude a aussi montré que dans la vallée du fleuve, il y'a un seul mode d'association alors que dans le Goulbi de Maradi, deux modes d'association existent avec une prédominance des cultures intercalaires. L'analyse a contribué à une meilleure connaissance des cultures associées au M. oleifera d'une part et, d'autre part, elle a permis de cerner les superficies allouées à ces systèmes d'utilisation des terres dans les zones d'étude mais, que les superficies moyennes sont significativement différentes. Les résultats ont également montré que parmi les cultures associées au $M$. oleifera, l'aubergine est la plus représentée dans la vallée du fleuve avec une proportion de $24 \%$ alors que dans le Goulbi de Maradi c'est plutôt la tomate qui est la plus représentée avec une proportion de $50 \%$. Les raisons avancées par les exploitants dans le choix des cultures associées au M. oleifera sont non seulement liés aux caractéristiques du milieu mais surtout aux enjeux socioéconomiques du fait que toutes les productions participent efficacement à la réduction de la vulnérabilité des populations.

\section{CONFLIT D'INTERET}

Les auteurs de ce manuscrit affirment par la présente déclaration qu'il n' y'a aucun conflit de d'intérêt de quelque forme que ce soit, ni entre les auteurs eux-mêmes, ni entre les auteurs et des tierces personnes. 


\section{REMERCIEMENTS}

Les remerciements des auteurs vont à l'endroit de tous ceux qui, de près ou de loin, ont contribué à la réalisation de ce travail. Il s'agit particulièrement des exploitants des sites ayant fait l'objet de cette étude.

\section{REFERENCES}

ANAFE-RAFT Sahel, 2006. Manuel d'agroforesterie à l'intention des établissements supérieurs du sahel. Bamako-Mali, 70p.

Burgess, PJ, Incoll LD, Corry DT, Beaton A, Hart BJ. 2004. Poplar (Populus spp) growth and crop yields in a silvoarable experiment at three lowland sites in England. Agrofor. Syst., 63: 157-169.

Fahey JW. 2005. M. oleifera: A Review of the Medical Evidence for Its Nutritional, Therapeutic, and Prophylactic properties. Part 1. Trees for Life Journal, 1: 5.

Foidl N, Makkar HPS, Becker K. 2001. Potentiel de Moringa oleifera en agriculture et dans l'industrie. Actes du séminaire sur Moringa oleifera du 29 octobre au 2 novembre 2001, Dar es Salaam, Tanzanie. $57 \mathrm{p}$.

Fuglie LJ. 2002. The Tree of Life, Dakar, Senegal, Western Africa. Church World Services; 40-60.

Gamatié M. 2001. Les systèmes de gestion du Moringa oleifera dans la vallée du fleuve Niger: cas de la zone de sarando. 11p.
Gamatié M. 2005. Description des Filières Feuilles de Moringa au Niger. INRAMoringanews-CTA ; 9p.

Gamatié M, Saint Sauveur (de) A. 2005. Fiche technico-économique sur les conditions de production et commercialisation de feuilles fraîches de Moringa au NIGER. CTA. $7 \mathrm{p}$.

Lawali S. 2003. Place du Moringa (Moringa oleifera) dans les Systèmes de production agricole au Niger: Cas des sites maraichers de la communauté urbaine de Niamey, Rapport d'étude, $35 \mathrm{p}$.

Mawouma S, Mbofung CM. 2014. Usages alimentaires de Moringa oleifera dans la région de l'Extrême-Nord Cameroun. Int. J. Biol. Chem. Sci., 8(4): 1847-1852. DOI : http://dx.doi.org/10.4314/ijbcs.v8i4.42

Rivest D, Olivier A. 2007. Cultures intercalaires avec arbres feuillus : quel potentiel pour le Québec ? The Forestry Chronicle, 83(4): 526-538.

Saint Sauveur (de) A. 1997. Le Moringa oleifera au Niger et en Inde, ou quand les agriculteurs préfèrent planter les arbres. Le Flamboyant: Silva 43 ; 1623.

Saint Sauver (de) A. 2005. Initiatives existantes de commercialisation internationale de feuilles de Moringa sous différentes formes. MoringanewsCTA-CDE, $7 \mathrm{p}$. 